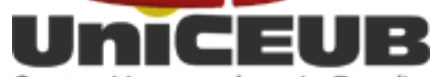

Centro Universitárı de Brasílı

CENTRO UNIVERSITÁRIO DE BRASÍLIA - UniCEUB

FACULDADE DE TECNOLOGIA E CIÊNCIAS SOCIAIS APLICADAS - FATECS
\end{abstract}

PROGRAMA DE INICIAÇÃO CIENTÍFICA

FERNANDA MAGALHÃES CAMPOS DA CUNHA

RENATA PEREIRA DE MACEDO

ENERGIA SOLAR - SISTEMA TRANSIENTE DE ENERGIA SOLAR: ESTUDO DA UTILIZAÇÃO DE ENERGIA SOLAR PARA O ABASTECIMENTO DO PLANO PILOTO 


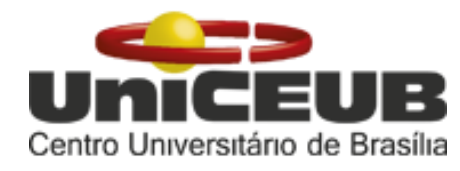

FERNANDA MAGALHÃES CAMPOS DA CUNHA

RENATA PEREIRA DE MACEDO

\title{
ENERGIA SOLAR - SISTEMA TRANSIENTE DE ENERGIA SOLAR: ESTUDO DA UTILIZAÇÃO DE ENERGIA SOLAR PARA O ABASTECIMENTO DO PLANO PILOTO
}

\author{
Relatório final de pesquisa de Iniciação Científica \\ apresentado à Assessoria de Pós-Graduação e \\ Pesquisa pela Faculdade De Tecnologia E \\ Ciências Sociais Aplicadas - FATECS \\ Orientação: Eugênia Cornils Monteiro Araújo
}




\section{RESUMO}

A energia solar vem se mostrando como uma alternativa a utilização de energias produzidas através de combustíveis fósseis; dentre os fatores que conduzem a isso está a redução de impactos ambientais na sua geração. O Distrito Federal integra uma localização geográfica propícia para a produção de energia fotovoltaica por ser uma região de grandes altitudes e por não possuir longos períodos chuvosos; a Asa Norte foi escolhida por ser a região em que o Centro Universitário de Brasília está localizado. O objetivo dessa pesquisa foi compreender a eficiência da geração de energia fotovoltaica, assim como investigar a viabilidade do aproveitamento desta energia na região escolhida, na intenção de que uma unidade consumidora de eletricidade virtual possa ser sua unidade geradora. Foi selecionada virtualmente uma amostra de edifícios na Asa Norte; e suas dimensões, coordenadas geográficas e situação de disponibilidade para aproveitamento solar foram checadas. A atividade em campo foi realizada para confirmar os dados obtidos no software de simulação do Centro de Referência para Energia Solar e Eólica Sérgio Brito e as dimensões adquiridas através do Google Earth, e identificar também possíveis obstruções ou problemas relacionados à implantação de painéis fotovoltaicos na cobertura do edifício escolhido. Foram medidas, calculadas e analisadas taxas de incidência solar, assim como irradiação e as angulações de zênite e azimute, de modo a verificar a eficiência de produção energética com placas em posição e tamanhos padrões. Determinou-se que a produção de energia para o edifício estudado na Asa Norte seria de um valor compreendido entre 3.197 e 5.754 quilowatts-hora por ano, distribuídos em doze painéis, no edifício em questão. Também foram analisados virtualmente outros três prédios aleatórios na Asa Norte, onde foi observado que, em geral, possuem espaço disponível em suas coberturas e com baixos índices de obstrução dos raios solares, concluindo assim haver uma captação similar ao edifício estudado inicialmente. Em resumo, foi concluído que a Asa Norte possui áreas que podem ser adequadas para instalação de painéis fotovoltaicos, dados os resultados estudados neste trabalho, ficando sugerida assim a viabilidade de implantação desse sistema para redução dos custos e redução dos impactos ambientais.

Palavras-chave: Asa Norte. Eficiência energética. Painéis fotovoltaicos. 
SUMÁRIO

1 INTRODUÇÃO -- 1

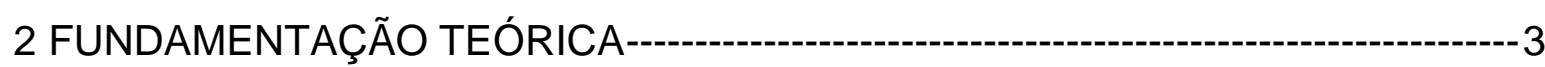

2.1 Matriz energética brasileira, geração distribuída e energia solar ------------3

2.2 Características elétricas dos painéis fotovoltaicos --- 6

2.3 Equações para cálculo da irradiação solar utilizando latitude, longitude,

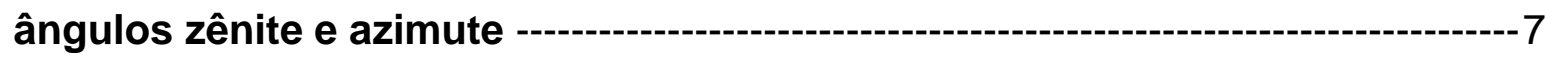

3 METODOLOGIA - 11

4 RESULTADOS E DISCUSSÕES -- 14

4.1 Cálculos de fluxo de irradiação solar --

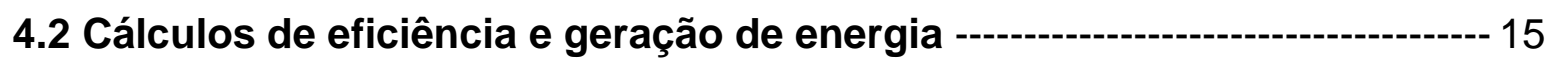

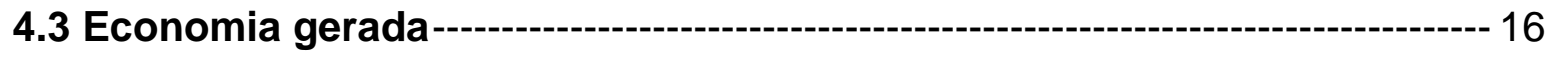

4.4 Posicionamento dos painéis fotovoltaicos -----

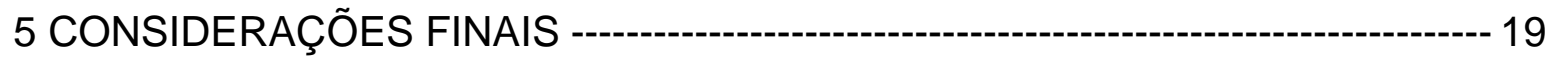

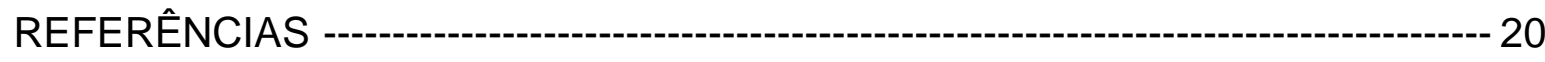




\section{INTRODUÇÃO}

A utilização de fontes renováveis para geração de energia vem se apresentando como uma alternativa concreta ao uso dos combustíveis fósseis. A necessidade de diversificar a forma como a energia é gerada, distribuída e utilizada é essencial para um processo de descarbonização da economia.

As principais motivações para estas mudanças são que os combustíveis fósseis são recursos finitos e que seu uso é o principal responsável pelo aumento de concentração de carbono na atmosfera.

Além dos problemas causados pelo uso do petróleo, a redução de disponibilidade e a instabilidade dos preços tem impulsionado a utilização de energias renováveis. A "horizontalização" da geração surge como uma oportunidade para mudança de paradigmas na área de energia (RIFKIN, 2003).

Dentre as fontes energias renováveis, a solar vem apresentando algumas vantagens como a redução progressiva no preço de seus equipamentos, o que tem motivado programas de incentivo governamental que favorecem sua utilização em grande parte do território brasileiro.

A inclusão da energia solar na matriz energética brasileira parece uma alternativa plausível por toda sua potencialidade e pela superação das dificuldades do passado. Por se tratar de uma energia que depende das condições de tempo, a ideia é que ela possa ser distribuída nas áreas que tem mais necessidade, e devolvida em créditos, ou em forma de energia ou mesmo gerando renda para seus fornecedores.

Mesmo com a necessidade de mudança nas formas de fornecimento da matriz energética ainda existem barreiras técnicas, econômicas, sociais e regulatórias para utilização do potencial de energia solar do Brasil. Dentre as barreiras técnicas existem às variações rápidas de potência com a passagem de nuvens, poeiras, que geram a utilização intensiva dos componentes, comprometendo sua vida útil (PERLOTTI et al., 2013). 
Outra questão técnica a ser considerada é que o aumento da radiação aumenta a capacidade de geração, entretanto a elevação da temperatura pode causar redução na eficiência do sistema (YADAV et al., 2013).

De acordo com Di Piazza et al. (2010), a simulação de painéis solares fotovoltaicos é um poderoso instrumento de análise destas variações temporais. Classicamente esta simulação é formulada utilizando um modelo de circuito equivalente com gerador-diodo, ao qual é adicionado o comportamento das células que formam um painel solar.

Esse processo designado como de geração distribuída, já ocorre em vários países e está crescendo como uma forma sustentável de fornecimento e obtenção de energia elétrica (LISITA, 2005).

A localização geográfica do Brasil entre trópicos favorece ainda mais a utilização da energia solar como fonte geradora de energia, com um potencial imenso espalhado pelas diversas regiões e períodos do ano. Uma área favorável às instalações de painéis seria Brasília, por ser uma região de grandes altitudes e não possuir longos períodos de chuva. Asa Norte, bairro nobre de Brasília, possui uma extensa quantidade de edifícios dos quais possuem espaços livres em suas coberturas, podendo assim ser conveniente às instalações de painéis solares.

O objetivo dessa pesquisa foi desenvolver um sistema de geração distribuída onde cada unidade consumidora é também uma unidade geradora de eletricidade virtual para uma localidade amostral da Asa Norte, Distrito Federal, utilizando energia solar para evidenciar oportunidades, dificuldades e possíveis alternativas dessa prática. Avaliar os programas de simulação adequados para o problema em questão. Também aplicar estudos do curso de Engenharia Civil, assim como seu desdobramento no estudo da Engenharia Elétrica. A publicação do projeto tem como ambição obter aspectos utilitários do sistema de energia solar e incentivar uma maior abertura para o uso deste tipo de sistema aos encarregados de obras públicas quanto a utilização de energia renovável. 


\section{FUNDAMENTAÇÃO TEÓRICA}

Nesse tópico foram abordados os temas que nortearam a realização deste trabalho como matriz energética mundial e brasileira, energia solar, geração distribuída e incentivos governamentais.

\subsection{Matriz energética brasileira, geração distribuída e energia solar}

Conforme Martins (2004), a matriz energética brasileira possui a maior parte de seu potencial fornecido pela energia proveniente das hidroelétricas, que não emitem poluentes para atmosfera, porém geram impactos que ainda não foram adequadamente avaliados e quantificados como, por exemplo, o impacto relativo as áreas cultiváveis, biomas inundados e deslocamento de populações, dentre outros.

Para incrementar a participação das energias renováveis na matriz energética mundial estão surgindo várias pesquisas e estudos dentre elas o exemplo ocorrido na cidade de San Antônio no Texas, onde foram realizadas diversas ações para dar início a Terceira Revolução Industrial proposta por Jeremy Rifkin (2003). Essa revolução tem como os quatro pilares:

1. A substituição de energias fósseis por energia renováveis;

2. A conversão das construções em usinas de captação e fornecimento de energia, ou seja, utilização da energia que está disponível;

3. O desenvolvimento de novas formas de armazenamento da energia, já que muitas energias de fluxo são intermitentes e necessitam de uma forma adequada de estocagem com baixos custos;

4. Redes e infraestruturas inteligentes - para realizar a transmissão e controle dessa energia horizontalizada deverá haver uma comunicação adequada em paralelo.

Existem estratégias formuladas até o ano de 2050 para a região de San Antônio, o acesso a investimentos e tecnologia (RIFKIN, 2012). A barreira maior para utilização desse meio foi, durante muito tempo, o alto custo e baixa eficiência dos sistemas de conversão desse tipo de energia. 
No Brasil há uma grande disponibilidade de áreas em que a incidência de radiação solar é satisfatória, como mostra a Figura 1. A distribuição de energia solar no Distrito Federal apresentada pelo mapa da Figura 2, tornou possível a análise da irradiação na região estudada.

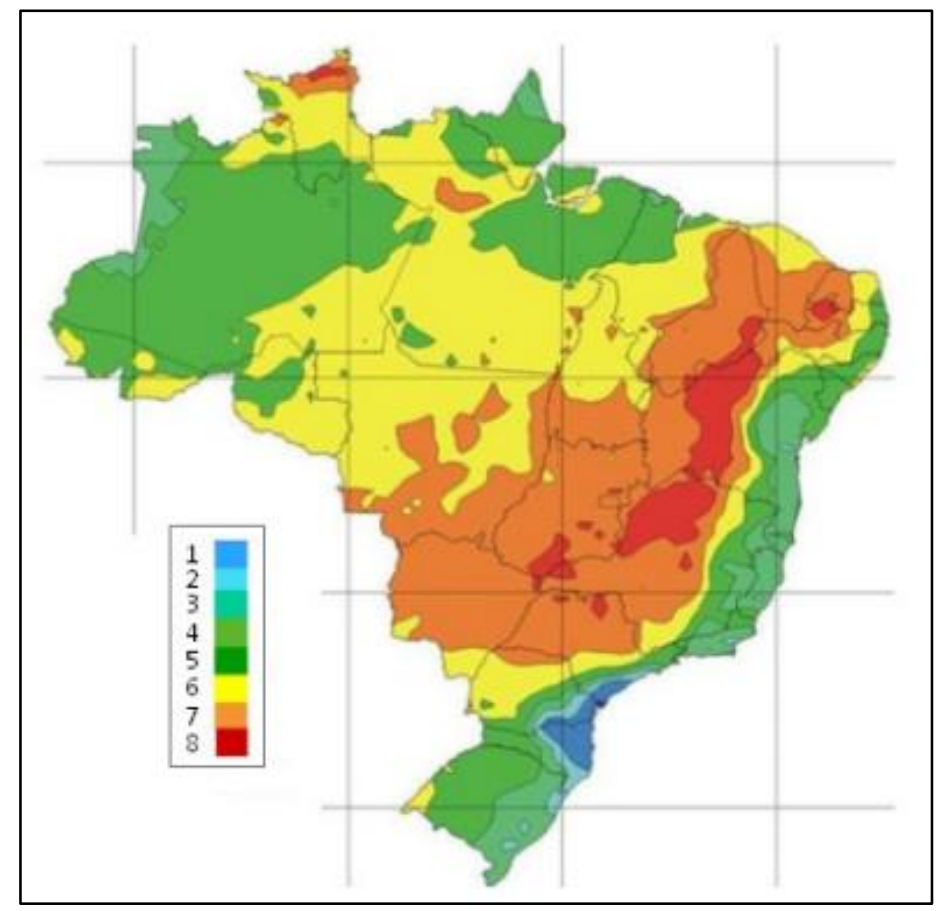

Figura 1 - Irradiação solar do Brasil no plano inclinado (Fonte: Adaptado do Atlas Brasileiro de Energia Solar)

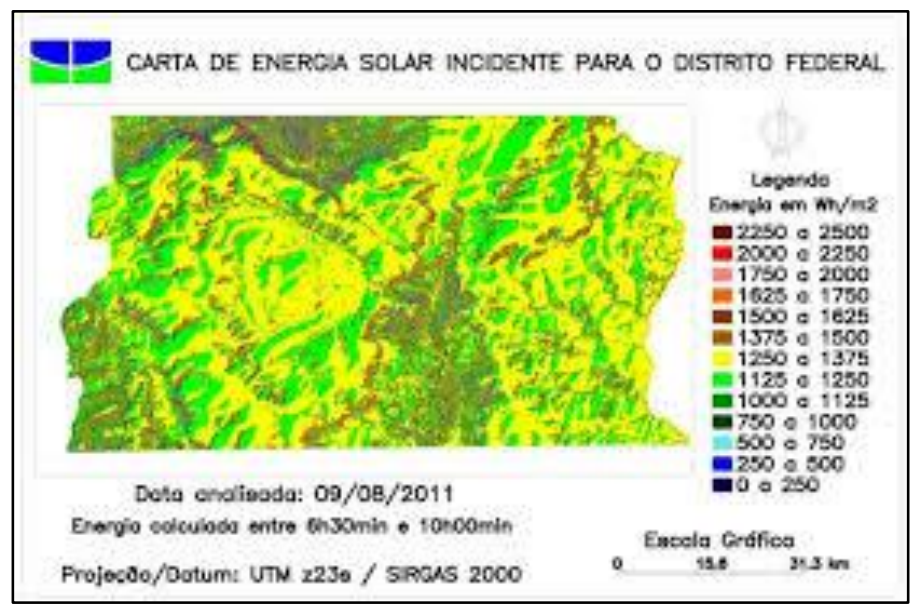

Figura 2 - Carta de distribuição de energia solar incidente para o Distrito Federal (Fonte: Adaptado dos Anais XVI Simpósio Brasileiro de Sensoriamento Remoto)

A classe que se destaca no mapa da figura 2 é a que varia de $1250 \mathrm{Wh} / \mathrm{m}^{2}$ a $1375 \mathrm{Wh} / \mathrm{m}^{2}$, e é visualmente acompanhada pela classe seguinte que possui 
variância de $1125 \mathrm{Wh} / \mathrm{m}^{2}$ a $1250 \mathrm{Wh} / \mathrm{m}^{2}$, que corresponde a aproximadamente $74 \%$ da área tratada no mapa. A análise justifica a implantação de sistemas de painéis fotovoltaicos na região do Distrito Federal.

Com o passar dos anos o custo de implantar de um sistema fotovoltaico está se reduzindo e assim, em contrapartida, a viabilidade de sua instalação está aumentando até mesmo para uso doméstico, conforme mostra a tabela 1.

A forma mais utilizada é do aproveitamento da energia solar para aquecimento de água, porém para proporcionar maiores ganhos para a sociedade existe o interesse na geração de energia elétrica por meio da utilização de painéis fotovoltaicos. Por ser um sistema de pequeno porte, os painéis solares podem ser instalados em fachadas e telhados de residências, estabelecimentos comerciais e industrias. Este sistema não necessita da utilização de baterias, diminuindo assim os custos e aumentando os intervalos entre as manutenções (DEMONTI, 1998).

\begin{tabular}{crrc}
\hline Aplicação & Potência & $\begin{array}{c}\text { Investimento } \\
\text { inicial } \\
\text { (R\$ mil) }\end{array}$ & $\begin{array}{c}\text { Custo nivelado } \\
\text { de geração } \\
\text { (R\$/MWh) }\end{array}$ \\
\hline Residencial & 5 & 38 & 602 \\
\hline Comercial & 10 & 69 & 541 \\
\hline Industrial & 100 & 591 & 463 \\
\hline
\end{tabular}

Tabela 1 - Custos da geração fotovoltaica (Fonte: EPE, 2012)

Os dados de experimentos realizados previamente podem ser utilizados como fonte comparativa para simulações matemáticas. Um desses experimentos foi realizado em Northumberland. Nele Wilshan (1996) relacionou a diferença das temperaturas do módulo e do ambiente para variadas irradiação da temperatura ambiental. Os dados são provenientes de um arranjo de módulos fotovoltaicos localizados no telhado de uma construção, e as medidas foram realizadas em uma semana quente de agosto. 


\subsection{Características elétricas dos painéis fotovoltaicos}

A energia fotovoltaica é gerada através da conversão da luz solar em corrente elétrica, por meio de placas construídas com fotocélulas produzidas a partir de um material semicondutor, como Silício cristalino (C-Si), Silício amorfo hidrogenado (aSi), Arsenieto de Gálio, Sulfeto de Cádmio e células CIGS (Cobre-Índio-GálioSelênio) (DEMONTI, 1998).

De acordo com Seguel (2009) uma célula fotovoltaica tem a capacidade de produzir entre $1 \mathrm{~W}$ e $2 \mathrm{~W}$, o que corresponde a uma tensão de $0,5 \mathrm{~V}$ e uma corrente elétrica de entre $2 \mathrm{~A}$ e $4 \mathrm{~A}$. Para captar níveis consideráveis de tensão e corrente, são necessárias ligações em série e paralelo dessas células fotovoltaicas, formando assim os painéis solares. Uma bateria de $12 \mathrm{~V}$ poderia ser suficientemente carregada com um painel contendo entre 33 a 36 células fotovoltaicas.

Intensidade da radiação solar e temperatura das células são fatores que influenciam diretamente as características elétricas e um painel. Com a variação de irradiação incidente no painel, a geração de corrente elétrica varia proporcionalmente. A expressão a seguir proposta por Gow, Manning (1999) apud Seguel (2009) "descreve a equação para a corrente fornecida por um módulo fotovoltaico":

$$
I=n_{P} \cdot\left[I_{L}-I_{S} \cdot\left[e^{\frac{q \cdot\left(\frac{V}{n_{S}}+\frac{I \cdot R_{S}}{n_{P}}\right)}{n \cdot k \cdot T}}-1\right]-\frac{\frac{V}{n_{S}}+\frac{I \cdot R_{S}}{n_{P}}}{R_{P}}\right]
$$

Onde:

I é corrente fornecida pelo painel ao circuito externo

$I_{L}$ é a corrente quiescente do indutor

$I_{S}$ é o valor máximo da corrente de carga

$k$ é a constante de Boltzmann

$n$ é o fator de idealidade 
$n_{P}$ é o número de células conectadas em paralelo do painel fotovoltaico

$n_{S}$ é o número de células conectadas em série do painel fotovoltaico

$q$ é a carga do elétron

$R_{P}$ é a resistência intrínseca paralelo do painel fotovoltaico

$R_{S}$ é a resistência intrínseca série do painel fotovoltaico

$T$ é a temperatura da célula

$V$ é a tensão fornecida pelo painel ao circuito externo

Demonti (1998) afirma também que o rendimento de uma placa fotovoltaica varia de acordo com sua composição. Essa eficiência é reduzida por fatores de conversão, de perdas na condução de energia através da fiação, de transformadores, no circuito do sistema e de elevadas temperaturas das células.

Comercialmente há disponibilidade de painéis com diferentes rendimentos, de $6 \%$ até aproximadamente $27 \%$, entretanto não são utilizadas placas com rendimento menor que $15 \%$.

\subsection{Equações para cálculo da irradiação solar utilizando latitude, longitude, ângulos zênite e azimute}

Para calcular a irradiação solar máxima a equação a seguir, apresentada por Duffie (1980), foi utilizada:

$$
I_{c b}=I_{0 n} \tau_{b} \cos \theta_{z}
$$

Onde:

$I_{c b}$ é a relação para determinar a radiação de céu limpo.

Para compreender como a incidência solar tem impacto na irradiação total gerada na superfície terrestre, ou mesmo sobre suas edificações, é necessário conhecer o sistema de posicionamento do sol em relação a terra. Assim dois ângulos são essenciais, o $\theta_{z}$ chamado de ângulo zenital, que indica a inclinação 
num sistema de coordenadas da posição do sol e sua perpendicular, e o ângulo $A$ chamado de ângulo de azimute que mostra o deslocamento desse ângulo com relação ao norte.

Para calcular esses ângulos são necessárias algumas variáveis como: latitude, longitude, ano, mês, dia, hora, minutos e segundos. Em Brasília a latitude é: -15,7801 e a longitude é: -47,9292.

A altitude pode ser calculada da seguinte forma:

$$
\alpha_{s}=90^{\circ}-\theta_{z}
$$

Embora a percepção geral conduza a ideia que a hora solar é a mesma que pode ser observada nos relógios das pessoas na terra, existe a hora solar, por estarmos tratando de luz e observar os princípios físicos que o tempo é relativo ao observador conforme a lei da relatividade de Einstein. Assim no momento de utilizar as horas, minutos e segundos deve ser feita uma adaptação para cálculo da hora solar:

$$
t_{s}=t_{s t}+4\left(L_{s t}-L_{l o c}\right)+E
$$

Onde:

$t_{s}$ é a hora solar

$t_{s t}$ é a hora padrão

$L_{s t}$ é a longitude de fuso horário

$L_{\text {loc é a longitude local }}$

E é a correção

$\mathrm{Na}$ pesquisa foi utilizada como longitude local de Brasília -47,9292, e a latitude horário como -15,7801. A hora padrão como 12 horas ou o zênite por se tratar do momento no qual ocorre a máxima incidência direta de raios solares.

Porém para cálculo da hora solar ainda foi necessário o fator de correção que segue a seguinte equação: 


$$
E=9,85 \sin 2 B-7,53 \cos B-1,5 \sin B
$$

Onde $B=\frac{(n-81) 360}{364}$ é um valor que depende do dia do ano $\mathrm{n}$.

Para calcular o ângulo zênite pode ser utilizada a seguinte equação:

$$
\cos \theta_{z}=\cos \emptyset \cos \delta \cos \omega+\sin \delta \sin \emptyset
$$

Onde, $\omega$ é o deslocamento angular do sol em relação ao meio dia e pode ser calculado através da seguinte forma:

$$
\omega=\left(t_{s}-12\right) * 15
$$

Já que quando for 12 horas não haverá deslocamento e $\omega$ será 0 . E o valor 15 multiplicando é o responsável por dividir os fusos horários de hora em hora. $O$ valor de $\phi$ utilizado na pesquisa foi de -15 por se tratar do trabalho ter sido realizado em Brasília.

O ângulo de azimute pode ser calculado através da seguinte equação:

$$
\sin A=\frac{-\cos \delta \sin \omega}{\cos \left(90-\theta_{z}\right)}
$$

A inclinação da terra com relação ao seu movimento de translação é outro fator que foi considerado, essa inclinação é dada pela equação a seguir, onde $n$ é o dia do ano:

$$
\delta=23,45 \sin \left[\frac{360}{365}(284+n)\right]
$$


Com todos esses fatores pôde ser calculada a transmitância que é a fração de luz com um comprimento de onda especifico que atravessa uma amostra de matéria seja essa no problema em questão a atmosfera.

A transmitância pode ser calculada através de variáveis relacionadas com o ângulo de azimute $A$ :

$$
\tau_{b}=\alpha_{0}+\alpha_{1} \exp \left(\frac{-k}{\cos \theta_{z}}\right)
$$




\section{METODOLOGIA}

Este trabalho, cuja finalidade pode ser classificada como prática, possui objetivo de fornecer informações sobre a geração de energia solar utilizando painéis fotovoltaicos, com foco no seu comportamento dinâmico.

Para sua execução foram utilizadas fontes secundárias de dados como: dados históricos, relatórios oficiais das agências de energia; informações, pesquisas bibliográficas, registros em geral, entre outros.

As etapas desse trabalho foram:

1. Fundamentação teórica dos conceitos;

2. Modelagem dinâmica dos sistemas em painéis fotovoltaicos - O sistema fotovoltaico será modelado como um sistema não linear em primeira ordem;

3. Seleção de possíveis telhados de prédios da asa norte para análise das condições técnicas para implantação de energia solar;

4. Escolha do local que foi utilizado para realizar a visita;

5. Medição de nível de irradiação no local e condições do telhado da edificação para aproveitamento de energia solar fotovoltaica;

6. Desenvolvimento de modelo térmico dos sistemas de placas fotovoltaicas, considerando o regime transiente térmico e de irradiação solar;

7. Validação do modelo - Comparação dos resultados obtidos na simulação do modelo com o simulador do CRESESB;

8. Análise do modelo e estimativa de sua utilização - comparação com os resultados da literatura e estabelecimento dos seus limites de utilização.

Foram selecionados três prédios em lugares da Asa Norte para simulação e estudo. Porém para validar as medidas adquiridas através da ferramenta do Google, - Google Earth, foi realizada uma visita à cobertura de um dos prédios previamente escolhidos. A cobertura do Bloco J do SQN (Setor de Quadras Norte) 307 foi escolhida por sua localização, pela máxima ausência de sombra, pela maior 
planificação apresentada pelo Earth e pelo contato com um dos inquilinos, como apresenta a figura 3. A visita foi realizada de $10: 00$ as 11:30 do dia 23 de março de 2016.

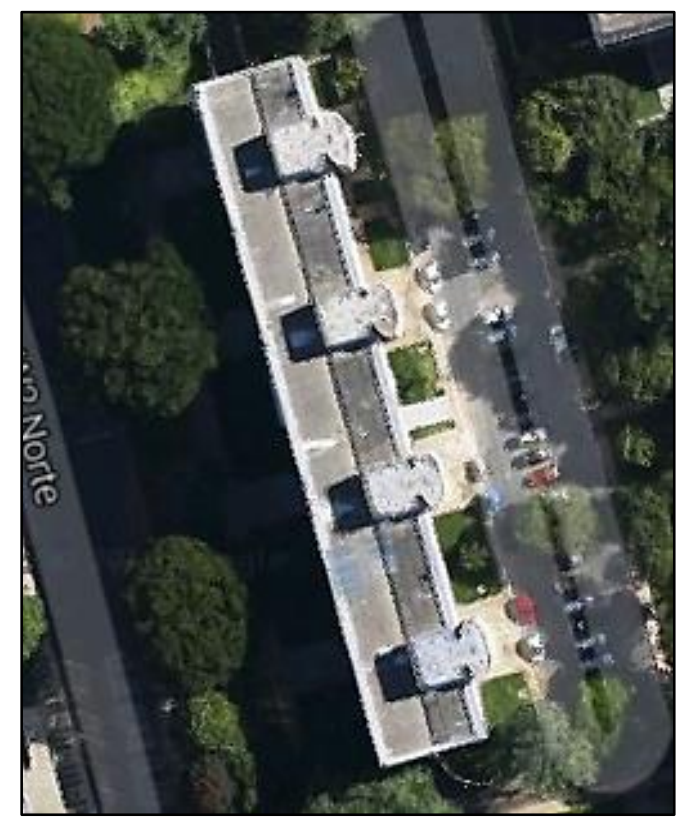

Figura 3 - Vista superior do edifício escolhido para visita (Fonte: Google Earth)

Para a elaboração desta pesquisa, foi levado em consideração somente estudos para as áreas comuns dos prédios, não tendo em vista o uso energético de cada apartamento. Sendo assim, foi perguntado ao síndico do edifício escolhido somente o consumo médio mensal do condomínio.

Para a validação das nossas coletas de dados, foi também verificado o fluxo de irradiação solar diária média no site do CRESESB (Centro de Referência para energia solar e Eólica Sergio Brito). As medidas encontradas na internet, seja pelo Google Earth ou pelo CRESESB não são completamente exatas, por isso foram levados ao local uma trena a laser, um piranômetro e um multímetro para medições in loco. Ao chegar ao local constatou-se que a cobertura do prédio não era plana como foi conferido no Google Earth, entretanto esta ainda foi considerada uma base plana para o projeto, por motivos de simplificação. 
Foram medidas simultaneamente a irradiação solar e a área da cobertura. Também foram aferidos os ângulos zênite e azimute da localização escolhida. Em uma experiência rápida da mensuração da irradiação solar foi conferida a diferença entre radiação direta e difusa. Enquanto o piranômetro captava a radiação solar direta e mostrava sua tensão no multímetro, posicionava-se uma mão próxima a ele a modo de fazer sombra sobre o piranômetro; observou-se que a radiação então captada, sendo difusa, foi muito menor do que quando os raios solares incidiam diretamente sobre o medidor.

Foi decidido que os futuros cálculos seriam realizados levando em consideração a instalação de doze placas virtuais, pois é necessário que existam espaços disponíveis para outras instalações, assim como o custo financeiro dos painéis. Uma simulação no AutoCAD foi realizada posicionando as placas com a face em sentido norte, angulação de $15^{\circ}$ e com área de 1,004 $\mathrm{m}^{2}$, de acordo com o Portal Solar.

Após coleta de dados, foi analisada a literatura e foram realizados estudos para obter valores de fluxo de irradiação, de geração de energia e de economia gerada no mês. Assim, calculou-se os valores em que se consideram perdas com condução por fiação e conversão, e a eficiência média real dos painéis fotovoltaicos, sendo utilizadas placas com rendimento de $15 \%$ e $27 \%$.

Todos os resultados foram considerados válidos para os três prédios escolhidos, pois possuem características semelhantes, porém só foi analisado a cobertura e a redução de gastos de um dos edifícios. 


\section{RESULTADOS E DISCUSSÕES}

\subsection{Cálculos de fluxo de irradiação solar}

$\mathrm{Na}$ cobertura do prédio estudado (figura 3) em que foram medidas as densidades de fluxo da radiação solar com um piranômetro e um multímetro obtevese uma leitura de $75,8 \mathrm{mV}$. Para sua transformação $\mathrm{em} \mathrm{W} / \mathrm{m}^{2}$ foi usada uma regra de três em que $81 \mu \mathrm{V}$ equivale a $1 \mathrm{~W} / \mathrm{m}^{2}$, portanto a captação em $\mathrm{W} / \mathrm{m}^{2}$ do prédio estudado foi de $0,935 \mathrm{~kW} / \mathrm{m}^{2}$.

Considerando que esse valor foi medido em horário de maior incidência de irradiação, foi utilizado apenas $60 \%$ do valor para cálculos, uma redução de $40 \%$, uma vez que há variação ao longo do dia. O cálculo surgiu simplesmente por uma questão de proporcionalidade.

Portanto o valor de irradiação captada ao longo do dia foi de $6,732 \mathrm{kWh} / \mathrm{m}^{2}$ dia como mostram os cálculos a seguir:

$$
\begin{gathered}
0,935 \frac{\mathrm{kW}}{\mathrm{m}^{2}} \times 60 \% \cong 0,561 \mathrm{~kW} / \mathrm{m}^{2} \\
0,561 \frac{\mathrm{kW}}{\mathrm{m}^{2}} \times 12 h=6,732 \frac{\mathrm{kWh}}{\mathrm{m}^{2} \mathrm{dia}}
\end{gathered}
$$

A partir do conhecimento de fluxo diário total, se for simulado o funcionamento de uma placa, deve ser levado em consideração possíveis perdas na sua utilização. Sendo elas climáticas ou funcionais, essas perdas alteram na irradiação captada pelo sistema. Entre elas pode-se destacar as falhas por sombreamento, por tempos fechados e chuvosos, por altas temperaturas, entre outras. Como não há um consenso na literatura em relação às percas possíveis no sistema, foi utilizada uma aproximação de $27 \%$ sobre esse componente. 
Portanto, levando em consideração tais perdas, e sua relevância nos cálculos de irradiação captada pelo sistema, o valor do fluxo seria de aproximadamente $4,914 \mathrm{kWh} / \mathrm{m}^{2} \mathrm{dia}$.

Ao comparar os resultados do cálculo acima com os dados disponibilizados pelo CRESESB, foi notado que os valores de irradiação média diária do mês de março, mês da visita in loco, são distintos, mas similares. A tabela a seguir mostra os valores disponibilizados pelo CRESESB em uma média diária mensal.

\begin{tabular}{|c|c|c|c|c|c|c|c|c|c|c|c|c|c|c|c|c|}
\hline \multirow{2}{*}{$\#$} & \multirow{2}{*}{ Ângulo } & \multirow{2}{*}{ Inclinação } & \multicolumn{14}{|c|}{ Irradiação solar diária média mensal [kWh/m².dia] } \\
\hline & & & Jan & Fev & Mar & Abr & Mai & Jun & Jul & Ago & Set & Out & Nov & Dez & Média & Delta \\
\hline$\square$ & Plano Horizontal & $0^{\circ} \mathrm{N}$ & 4,67 & 5,58 & 4,53 & 5,00 & 4,72 & 4,75 & 4,97 & 5,50 & 5,25 & 4,69 & 4,75 & 4,72 & 4,93 & 1,05 \\
\hline$\nabla$ & Ângulo igual a latitude & $16^{\circ} \mathrm{N}$ & 4,35 & 5,35 & 4,56 & 5,39 & 5,42 & 5,67 & 5,86 & 6,14 & 5,43 & 4,57 & 4,45 & 4,35 & 5,13 & 1,79 \\
\hline$\nabla$ & Maior média anual & $19^{\circ} \mathrm{N}$ & 4,26 & 5,27 & 4,54 & 5,42 & 5,51 & \begin{tabular}{|l|l|} 
& 5,81 \\
\end{tabular} & 5,99 & 6,21 & 5,43 & \begin{tabular}{|l|}
4,52 \\
\end{tabular} & 4,37 & 4,26 & 5,13 & 1,95 \\
\hline$\nabla$ & Maior mínimo mensal & $6^{\circ} \mathrm{N}$ & 4,57 & 5,53 & 4,57 & 5,18 & 5,02 & 5,13 & 5,34 & 5,78 & 5,35 & \begin{tabular}{|l|l|}
5,67 & -10 \\
\end{tabular} & 4,66 & 4,61 & 5,04 & 1,21 \\
\hline
\end{tabular}

Tabela 2 - Irradiação solar diária média mensal durante um ano (Fonte: CRESESB)

Uma vez que na pesquisa foram definidas um número de doze placas a serem instaladas virtualmente, foi necessário calcular o fluxo de irradiação de acordo com a área de superfície dos painéis. Sendo que cada placa em tamanho padrão possui área de $1,004 \mathrm{~m}^{2}$, os doze painéis possuem uma área de trabalhabilidade de $12,048 \mathrm{~m}^{2}$. Assim, o fluxo de irradiação solar calculada na área dos painéis ao longo do dia é de 59,204 kWh/dia, e 1776,12 kWh/mês ao longo do mês, como mostram os cálculos a seguir:

$$
\begin{aligned}
& 4,914 \frac{k W h}{m^{2} d i a} \times 12,048 m^{2}=59,204 \frac{k W h}{d i a} \\
& 59,204 \frac{k W h}{d i a} \times 30 \text { dias }=1776,12 \frac{k W h}{m e ̂ s}
\end{aligned}
$$

\subsection{Cálculos de eficiência e geração de energia}

Com fluxo de 1776,12 kWh/mês na área estudada, foi calculado a geração de energia de acordo com a eficiência de uma placa fotovoltaica padrão presente 
no mercado. Comercialmente há disponibilidade de painéis com diferentes rendimentos, de $6 \%$ até aproximadamente $27 \%$, entretanto não são utilizadas placas com rendimento menor que $15 \%$. Essa eficiência pode ser reduzida de acordo com seu componentes, por perdas na condução da energia por fiação, por sujeira nas placas, por energia reativa, entre outras. A tabela a seguir mostra a geração de energia média mensal do sistema, e sua economia, de acordo com sua eficiência.

\begin{tabular}{c|c|c}
\hline Eficiência & Geração de Energia & Economia (\%) \\
\hline $15 \%$ & $266,42 \mathrm{kWh} /$ mês & $13,32 \%$ \\
\hline $27 \%$ & $479,55 \mathrm{kWh} /$ mês & $23,98 \%$ \\
\hline
\end{tabular}

Tabela 3 - Geração de energia e economia de acordo com a eficiência de cada placa fotovoltaica

\subsection{Economia gerada}

Com o conhecimento do consumo de energia elétrica do prédio, foi possível calcular uma economia em seus gastos com energia elétrica. Seu uso de energia mensal varia de 1900 kWh a 2100 kWh nas áreas comuns.

Após os cálculos de geração de energia através do sistema de doze placas fotovoltaicas e com os dados de consumo do edifício foi possível calcular a economia em gastos de energia mensal média. A tabela 3, no item anterior, apresentou a economia gerada em uma média de consumo geral de $2000 \mathrm{kWh}$ com sistemas de eficiência diferentes.

\subsection{Posicionamento dos painéis fotovoltaicos}

Simulando a instalação do sistema de placas solares, foi decidido que o sistema seria distribuído em três grupos de quatro painéis. Este tipo de locação foi escolhido por manter as placas distantes umas das outras, podendo assim ser 
evitado um maior aquecimento de suas células, o que geraria uma queda de eficiência (BRASIL, 2016).

Outros fatores que levaram a essa escolha de instalação foi o grande espaçamento entre as placas, facilitando a manutenção e a mobilidade de funcionários, e também a não colocação de placas onde possa ter tanto sombreamento vindo das coberturas dos elevadores. Dentre os pontos negativos podemos destacar o gasto extra com fios condutores. A pouca quantidade de painéis solares utilizados na instalação virtual é decorrente da restrição de capital do condomínio.

Para este relatório, foram feitas simulações no AutoCAD da distribuição dos painéis fotovoltaicos nos três edifícios. Nas figuras 4 e 5 foram projetadas uma planta dos prédios, já a figura 6 mostra as placas em 3D com a angulação escolhida de acordo com o melhor rendimento pesquisado no prédio da SQN 307. Por fim as placas ficaram com a face apontada para o norte e com uma angulação de $15 \%$ pois locadas assim gerariam um melhor rendimento (PORTAL SOLAR).

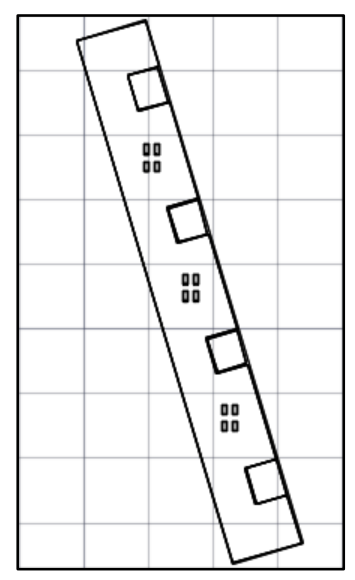

Figura 4 - Vista em planta da simulação do prédio do SQN 307 


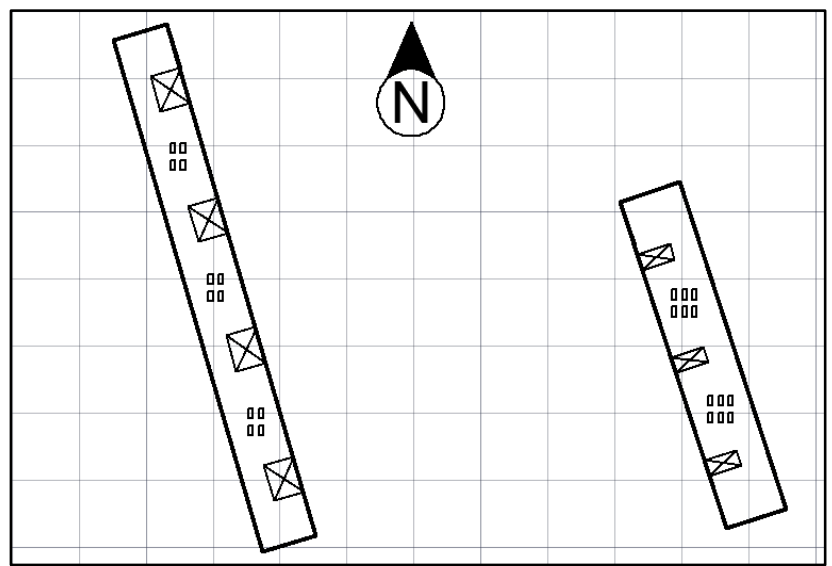

Figura 5 - Vista em planta da simulação dos prédios do SQN 409 e do SHCGN 708, respectivamente

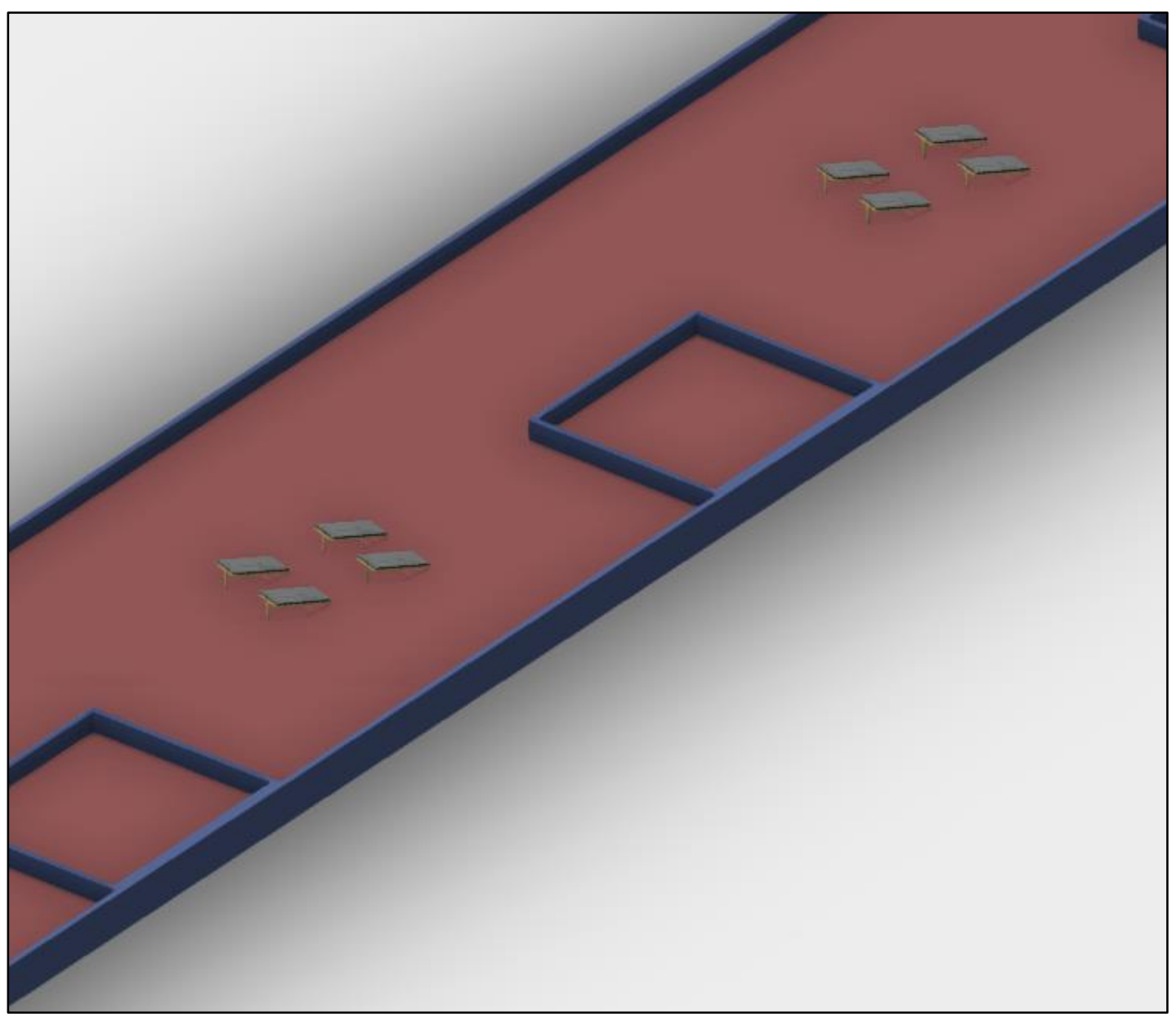

Figura 6 - Vista 3D da cobertura simulada do prédio do SQN 307 


\section{CONSIDERAÇÕES FINAIS}

De acordo com os cálculos realizados nesse trabalho, foi concluído que o edifício poderia gerar energia entre $266,42 \mathrm{kWh} /$ mês e $479,55 \mathrm{kWh} / \mathrm{mês}$, dependendo da eficiência da placa fotovoltaica escolhida. $E$ com base na informação de consumo do prédio, haveria uma redução de gastos entre aproximadamente $13 \%$ e $24 \%$ na conta de luz das áreas comuns. Todos os dados coletados são uma estimativa do real, pois há variâncias e aproximações foram utilizadas.

Foram feitas as validações de resultados do site CRESESB, onde é informado o fluxo médio diário mensal de irradiação solar de acordo com sua latitude e longitude, dado que o site disponibiliza como um único fluxo para toda Brasília.

Com a elaboração deste trabalho, foi visto que a implantação de placas fotovoltaicas nos edifícios residenciais da Asa Norte poderia ter certa utilidade, pois economizaria a energia vinda da rede pública, além de contribuir com o meio ambiente por ser uma fonte limpa. Para o estudo em questão, caso fossem consideradas todas as perdas do sistema, foi constatado que os ganhos energéticos seriam limitados, daí surge a necessidade de um estudo mais aprofundado sobre os custos de aquisição do sistema e o tempo de retorno do investimento.

Com este projeto, compreendeu-se sobre a viabilidade dessa forma de geração distribuída e como ela funciona. Assim como o trabalho em campo, a bibliografia consultada gerou novos conhecimentos na área de Engenharia e energias renováveis, o que resultou interesses em novas pesquisas. 


\section{REFERÊNCIAS}

ASSOCIAÇÃO BRASILEIRA DE NORMAS TÉCNICAS. NBR ISO 9001:2008 - Sistema de gestão da qualidade - Requisitos Rio de Janeiro: ABNT, 2008.

AZEVEDO, George Fernandes; DE SOUZA, Newton Moreira. Estimativa e análise da distribuição espacial da energia solar incidente para a região do Distrito Federal. Universidade de Brasília. Brasíia, 2013.

BRASIL Junior, A.C.P. Dynamical modeling and simulation of PV-solar panels. In VI CBENS Congresso Brasileiro de Energia Solar, Belo Horizonte, Minas Gerais, Brasil. 2016

BURSZTYN, M.; DRUMMOND, J. A.; NASCIMENTO, E.P. Como escrever (e publicar) um Trabalho Científico. Rio de Janeiro, Garamond, 2010

CRESESB. Potencial solar: SunData. Disponível em: http://www.cresesb.cepel.br/index.php\#data. Acessado em 27/08/2016.

DEMONTI, Rogers. Sistema de co-geração de energia a partir de painéis fotovoltaicos. 1998. Tese de Doutorado. Universidade Federal De Santa Catarina.

DI PIAZZA, M. C.; RAGUSA, A.; LUNA, M.; VITALE, G. A Dynamic Model of a Photovoltaic Generator Based on Experimental Data - ICREPQ- Granada, 2010.

DUFFIE, John A.; BECKMAN, William A. Solar engineering of thermal processes. 1980.

EPE. Empresa de Pesquisa Energética. Nota técnica. Análise da Inserção da Geração Solar na Matriz Elétrica Brasileira. Rio de Janeiro, Maio de 2012.

JONES, A. D., UNDERWOOD, C.P. A thermal model for Photovoltaic Systems, Newcastle, UK, 2000.

LISITA, O. Sistemas Fotovoltaicos Conectados à Rede: Estudo de caso - 3kWp instalados no estacionamento do IEE-SP. São Paulo: USP, 2005. 87 p. Tese Mestrado) - Instituto de Física, Programa de Mestrado em Energia. Universidade de São Paulo, São Paulo, 2005.

MARCONI, M. A.; LAKATOS, E. M. Técnicas de Pesquisa: Planejamento e Execução de Pesquisas, amostragens e técnicas de pesquisas, elaboração, análise e interpretação de dados. $6^{a}$ edição. São Paulo: Atlas, 2007.

MARTINS, Fernando R. et al. Levantamento dos recursos de energia solar no Brasil com o emprego de satélite geoestacionário. O Projeto Swera. Revista Brasileira de Ensino de Física, v. 26, n. 2, p. 145 - 159, (2004). Disponível em www.sb_sica.org.br. Acessado em 26/12/2005.

PERLOTTI, E.; CAMARGO, F.; GRANVILLE, A.; DE ALMEIDA CUNHA, G. R.; PEREIRA, M. V. F.; KEMAN, R Setorial de sistemas fotovoltaicos da abinne. Proposta para Inserção da Energia Solar Fotovoltaica na Matriz Elétrica Brasileira: Estudo do grupo. $1^{\underline{a}}$ ed. São Paulo: Ed. Edgard Blücher Ltda, 2013.

PORTAL SOLAR. A melhor direção do painel solar fotovoltaico. Disponível em: http://www.portalsolar.com.br/a-melhor-direcao-do-painel-solar-fotovoltaico.html. Acessado em 22/08/2016. 
RIFKIN, Jeremy. A economia do hidrogênio. A criação de uma fonte de energia e a redistribuição de poder na Terra. São Paulo: M. Books, 2003.

RIFKIN, J.; LAITNER, J. A. S.; EASLEY, N. Leading the Way Forward to the Third Industrial Revolution. San Antônio, 2009. Disponível em

http://www.thethirdindustrialrevolution.com/MasterPlan/index_SanAntonioMasterPlan_book.html\#/2. Acessado em 19/01/2015.

RIFKIN, Jeremy. A Terceira Revolução Industrial. São Paulo: M. Books, 2012.

RÜTHER, R.; ZILLES, R. Eletricidade solar para os telhados do Brasil. Valor Online, São Paulo, 2009. Disponível em

https://www.lepten.ufsc.br/publicacoes/solar/eventos/2008/ENTAC/salamoni_ruther.pdf. Acessado em 17/01/2015.

SEGUEL, Julio Igor López. Projeto de um sistema fotovoltaico autônomo de suprimento de energia usando técnica MPPT e controle digital. 2009. Tese de Doutorado. Universidade Federal de Minas Gerais.

WILSHAN, A. R., BATES J. R. AND PEARSALL N. M. Photovoltaic module operating temperature effects: In Proceeding of Eurosun, 96 páginas, pp. 940 -944, 1996.

YADAV, P.; BRIJESH, T.; LOKHANDE, M.; KUMAR, M. Estimation of steady state and dynamic parameters of low concentration photovoltaic system. Solar Energy Materials and Solar Cells, v. 112, p. 65-72, 2013. 